\title{
Caladores e homogeneizadores utilizados na amostragem de grãos em unidades
} armazenadoras

\section{Grinders and homogeneiers used in grain sampling in storage units}

\author{
Osvaldo Resende \\ Instituto Federal Goiano -Campus Rio Verde \\ E-mail: osvresende@yahoo.com.br \\ OrclD: https://orcid.org/0000-0001-5089-7846
}

José Ronaldo Quirino

Caramuru Alimentos S.A.

E-mail: zeronaldo@caramuru.com

OrclD: https://orcid.org/0000-0003-4668-5546

Elivânio Santos Rosa

Caramuru Alimentos S.A.

E-mail: elivanio@caramuru.com

OrclD: https://orcid.org/0000-0002-9219-9592

Tiago Abreu de Souza

Caramuru Alimentos S.A.

E-mail: tiago@caramuru.com

OrclD: https://orcid.org/0000-0001-5739-7043

Carlos André Rodrigues Queiroz

Caramuru Alimentos S.A.

E-mail: carlos.andre@caramuru.com

OrclD: https://orcid.org/0000-0001-5014-6591

Resumo: A amostragem e homogeneização de grãos, que envolve as ações de retirada de amostra, diluição e a confecção da amostra de trabalho, tem importância essencial na representatividade e na classificação do lote comercializado. As unidades armazenadoras devem utilizar métodos de amostragem que ofereçam segurança na coleta e na classificação do produto, gerando os descontos necessários e otimizando as operações unitárias do pré-processamento dos grãos. Os equipamentos homogeneizadores de grãos devem ser eficientes na uniformização e divisão da amostra, além de apresentar rapidez e baixo nível de ruídos durante a operação. Assim, o objetivou-se com o presente estudo detalhar os procedimentos e os equipamentos utilizados para amostragem, homogeneização e diluição (redução) de amostras de trabalho, na determinação da qualidade de grãos no recebimento e na expedição em unidades armazenadoras. Foram analisados os equipamentos para amostragem de grãos: sonda pneumática, calador composto manual 1,8 m de latão com três estágios; calador composto manual 2,1 m em alumínio com três estágios; calador composto manual 2,10 m de um estágio e amostrador tipo pelicano. Também foram descritos os homogeneizadores de grãos: Boerner, quarteador multicanais redutor 16:1 e quarteador multicanais redutor 4:1. Assim, as unidades armazenadoras devem utilizar métodos de amostragem que ofereçam segurança na coleta e na classificação do produto, gerando os descontos necessários e otimizando as operações unitárias do pré-processamento dos grãos. Os equipamentos homogeneizadores de grãos devem ser eficientes na uniformização e divisão da amostra, além de apresentar rapidez e baixo nível de ruídos durante a operação.

Palavras-chave: Amostra de trabalho. Amostragem de grãos. Caladores.

Abstract: Sampling and homogenization of grains, which involves the actions of sample withdrawal, dilution and the preparation of the working sample, are essential in the representativeness and classification of the commercialized batch. Storage units should use sampling methods that provide safe collection and 
classification of the product, generating the necessary discounts and optimizing unit operations of grain preprocessing. The grain homogenizers must be efficient in the uniformization and division of the sample, besides being fast and low noise level during the operation. Thus, the objective of this study was to detail the procedures and equipment used for sampling, homogenization and dilution (reduction) of work samples, in the determination of the quality of grains upon receipt and dispatch in storage units. The equipment for grain sampling (pneumatic probe, manual composite calender $1.8 \mathrm{~m}$ brass with three stages, $2.1 \mathrm{~m}$ manual composite caliper with three stages, manual composite caliper $2.10 \mathrm{~m}$ of one stage and sampler pelican type. Also described the grain homogenizers Boerner, 16:1 multi-channel reducer and 4:1 multi-channel reducer. Therefore, the storage units must use sampling methods that offer security in the collection and classification of the product, generating the necessary discounts and optimizing the unit operations of the pre-processing of the grains. The grain homogenizing equipment must be efficient in standardizing and dividing the sample, in addition to presenting speed and low level of noise during operation.

Keywords: Grinders. Sample of work. Sampling of grains.

Data de recebimento: 03/05/2018

Data de aprovação: 11/06/2020

DOI: https://doi.org/10.30612/agrarian.v13i50.8039

\section{Introdução}

A classificação e o estabelecimento do padrão de qualidade de grãos no Brasil são regulamentados por normas estabelecidas pelo Ministério da Agricultura Pecuária e Abastecimento (MAPA), que definem os defeitos dos grãos e estabelece os limites máximos permitidos, para efeito de enquadramento em tipos específicos.

A acuidade da classificação, além do conhecimento das definições de cada defeito, é também fortemente influenciada pelos procedimentos de amostragens de grãos e pela preparação da amostra para o trabalho de análise. $\mathrm{Na}$ amostragem deve-se retirar uma porção representativa do material, que mantenha fidedignamente as características qualitativas destes lotes analisados. Erros na amostragem ocasionam interpretações errôneas do real atributo do lote, prejudicando sempre uma das partes envolvidas na comercialização e aumentando custos industriais, logísticos, estadias entre outros (GLÓRIA, 2008).

Adjacente à utilização de equipamentos adequados para amostragem, deve-se atentar para o preparo e a diluição da amostra, tornando-a homogênea e em um volume adequado para o trabalho de análise e para que seja representativa do lote negociado.

A determinação das características da massa de grãos, por meio de uma amostra, envolve as etapas de coleta (amostragem), preparo (subamostragem) e a análise (classificação) para aceitação ou não do lote. Estes procedimentos constituem o plano amostral das empresas. Cada uma destas etapas fornece informações importantes e estão sujeitas a variações e a erros, contribuindo para a variabilidade total associada às análises (WHITAKER, 1977; GLÓRIA, 2008).

Glória (2008) define a amostragem como sendo a obtenção, por meio de uma limitada quantidade de grãos (amostra), de informações sobre um ou vários parâmetros de interesse, visto que não é possível avaliar toda a massa de grãos. Desta forma, a amostragem assume destaque já que é responsável por gerar um resultado representativo de um lote, para uma classificação mercadológica.

Segundo Parizzi (1999), a classificação de grãos é realizada por meio da determinação das características intrínsecas e extrínsecas do produto, com base em padrões previamente elaborados, sendo um instrumento disponível para indústria e exportadoras no controle de qualidade de um produto agrícola.

Whitaker et al. (2011) estudando amostragem para determinação de micotoxinas em grãos relatam que para cada plano de amostra, os riscos de erros são definidos pelo método de amostragem, tamanho da amostra, a preparação da subamostra, o número de análises e o método de análise. Além disso, os mesmos autores reforçam que o tamanho da amostra também interfere na variabilidade, e que quanto maior a amostra, menor será a variação.

Paulsen et al. (2007) relatam que apenas uma pequena amostra, sujeita a vieses e variabilidade, representa um carregamento de produto e o resultado é uma estimativa das propriedades de todo o lote. Segundo os autores existem diversas fontes de variação como: 1) distribuição desigual de grãos e impurezas; 2) procedimento de amostragem inadequado ou insuficiente; e 3) medições imprecisas. 
A Instrução Normativa (IN) MAPA n 29/2011 (Brasil, 2011a) define que um sistema de amostragem compreende um conjunto de equipamentos e normas operacionais que visam à obtenção de amostras representativas de uma carga ou lote de mercadorias que estão sendo avaliadas. Essa norma exige que nas unidades armazenadoras a granel tenha-se a utilização de amostradores do tipo calador composto que possibilite a obtenção de subamostras em diferentes alturas da carga, e recomenda a utilização de calador tipo pneumático e amostradores de fluxo. Em relação à homogeneização de amostras a referida norma estabelece que todas as unidades armazenadoras devem possuir um sistema de homogeneização, sem, contudo, descriminar os equipamentos adequados.

A IN MAPA n ${ }^{\circ} 54 / 2011$ aprova os requisitos e critérios para credenciamento, junto ao MAPA de pessoas jurídicas para executar serviços de classificação de produtos vegetais e seus sub-produtos com base nos padrões oficiais de classificação, e estabelece que estas empresas devem ter equipamentos próprios e compatíveis com as atividades executadas que devem estar aferidos e calibrados e em perfeito estado de conservação (BRASIL, 2011b). Além disso, para homogeneização estabelece como obrigatório um homogeneizador e quarteador de no mínimo 16 canais.

Nos procedimentos adotados em outros países exportadores ou importadores de grãos, tem-se por exemplo, as exigências estabelecidas pela legislação argentina e descritas na norma XXXII da Resolução da Secretaria de Agricultura, Ganadería y Pesca (SAGyP) $n^{\circ}$ 1075/94 (SENASA, 1994). Este documento contempla os procedimentos e equipamentos para amostragem, determinando que a homogeneização e divisão da amostra sejam realizadas com o equipamento Boerner ou outro que produza resultados similares.

$\mathrm{Na}$ classificação oficial de grãos nos Estados Unidos, quando executada pelo United States Departament of Agriculture (USDA) nas situações de exportação, as operações de homogeneização e redução das amostras são realizadas utilizando-se o homogeneizador tipo Boerner conforme procedimento descrito no Manual de Inspeção de Grãos (USDA, 2013).

Para os países da União Europeia, o regulamento descreve que a amostragem é um procedimento que exige um método e equipamentos adequados para a tarefa (ISO, 2011). A análise sobre as características de um lote ou interpretação dos resultados torna-se desnecessária se a amostra não for representativa do lote original. Complementarmente, ressalta que os erros de amostragem, definidos como sendo a diferença entre as características da amostra e as do lote avaliado ocorrem principalmente em função da heterogeneidade da amostra, dos erros associados aos equipamentos utilizados na amostragem e também ao método utilizado.

A amostragem de grãos a granel com a utilização de equipamentos como calador composto manual com um, dois ou três estágios ou mesmo com as sondas pneumáticas, pode resultar em números e posições insuficientes para obtenção de uma amostra representativa. Os equipamentos utilizados na preparação da amostra, tais como baldes e caixotes, por ter interferência e vícios do operador, podem prejudicar as exigências em acuidade do processo.

O amostrador tipo pelicano é usado durante a movimentação do material na linha de amostragem de grãos. Este amostrador é útil para amostras em rações, grãos e farelos, enquanto os veículos estão sendo descarregados (FAO, 2017).

A IN MAPA 54/2011, regulamenta sobre as empresas credenciadas no MAPA, e faz referência aos equipamentos exigidos, no entanto, apenas para classificação oficial de produtos nos casos em que são obrigatórios (BRASIL, 2011).

Assim, o objetivou-se com o presente estudo detalhar os procedimentos e os equipamentos utilizados para amostragem, homogeneização e diluição (redução) de amostras de trabalho, na determinação da qualidade de grãos no recebimento e na expedição em unidades armazenadoras.

\section{Caladores e amostradores}

Os caladores são equipamentos manuais utilizados para retirada de amostras a granel em caminhões e em superfícies de silos. Já os amostradores mecânicos (pneumáticos) são equipamentos compostos por um sistema de coleta por fluxo de ar, no qual há penetração da haste na massa de grãos pelo acionamento do comando hidráulico que posiciona o local e especifica o número de pontos amostrados. A haste coletora dispõe de dois tubos, sendo um com diâmetro interno de 0,0442 m, outro externo de 0,0662 m e comprimento de $1,90 \mathrm{~m}$. O ventilador promove um fluxo de ar descendente entre os tubos externo e interno, e este fluxo ao atravessar a massa de grãos coletada pela ponteira (diâmetro de 0,037 m) desloca os grãos, de forma ascendente pelo tudo interno, que apresenta outro fluxo de ar que succiona a massa até o tubo coletor, por onde a amostra é conduzida até o reservatório de grãos (Figura 1). 
prejuízo para as partes envolvidas. Também manutenções periódicas para verificação de desgastes, limpezas dos sistemas de dutos e mangueiras, troca de óleo hidráulico são fundamentais para o bom desempenho deste equipamento.

A verificação da eficiência dos equipamentos de amostragem é de fundamental importância, já que devem fornecer as informações reais do lote, referentes aos atributos teor de água, teor de impurezas, tipos de impurezas, grãos quebrados e matérias estranhas. Essas informações podem alterar o planejamento do uso de peneiras e fluxos de entrada de grãos nas máquinas e nas operações pós-colheita da unidade armazenadora.

\section{Homogeneizadores de amostras}

Os homogeneizadores do tipo Boerner e os quarteadores de multicanais são frequentemente utilizados para uniformização e divisão de amostras. Outras maneiras utilizadas no mercado para homogeneização de amostras, como caixote de madeira e balde apresentaram desempenho não satisfatório em relação a amostra originalmente preparada, quando foi utilizado tamanho de amostra conforme IN MAPA $n^{\circ}$ 11/2007 (BRASIL, 2007) e não são adequados para a homogeneização e redução de amostras de grãos por comprometerem o resultado da análise qualitativa do produto (QUIRINO, 2017).

Os homogeneizadores e diluidores do tipo Boerner, quarteador multicanal 16:1 e quarteador multicanal 4:1 foram semelhantes na redução e homogeneização de amostras de grãos de soja, sendo recomendados para essas operações durante a classificação de grãos (QUIRINO, 2017).

O quarteador multicanal redutor $16: 1$ tem as dimensões de $0,32 \mathrm{~m}$ de largura, 0,6 $\mathrm{m}$ de comprimento por $1,20 \mathrm{~m}$ de altura. Consiste na montagem de quatro pequenos quarteadores (estágios), um abaixo do outro, desde a moega de descarga do equipamento (Figura 4). O primeiro e o terceiro quarteadores têm 12 canaletas (seis para a amostra e seis para o descarte) com espessura média de 0,0254 m; e o segundo e quarto quarteadores têm 11 canaletas (seis para o descarte e cinco para a amostra) com espessura média de $0,0253 \mathrm{~m}$ e dimensões maiores das canaletas laterais de $0,0392 \mathrm{~m}$. Com a abertura da moega, o produto atravessa o primeiro quarteador, sendo parte destinada à amostra e parte descartada e, assim, sucessivamente até a subdivisão para o recipiente da amostra de trabalho e a outra parte, de maior volume, para o descarte.
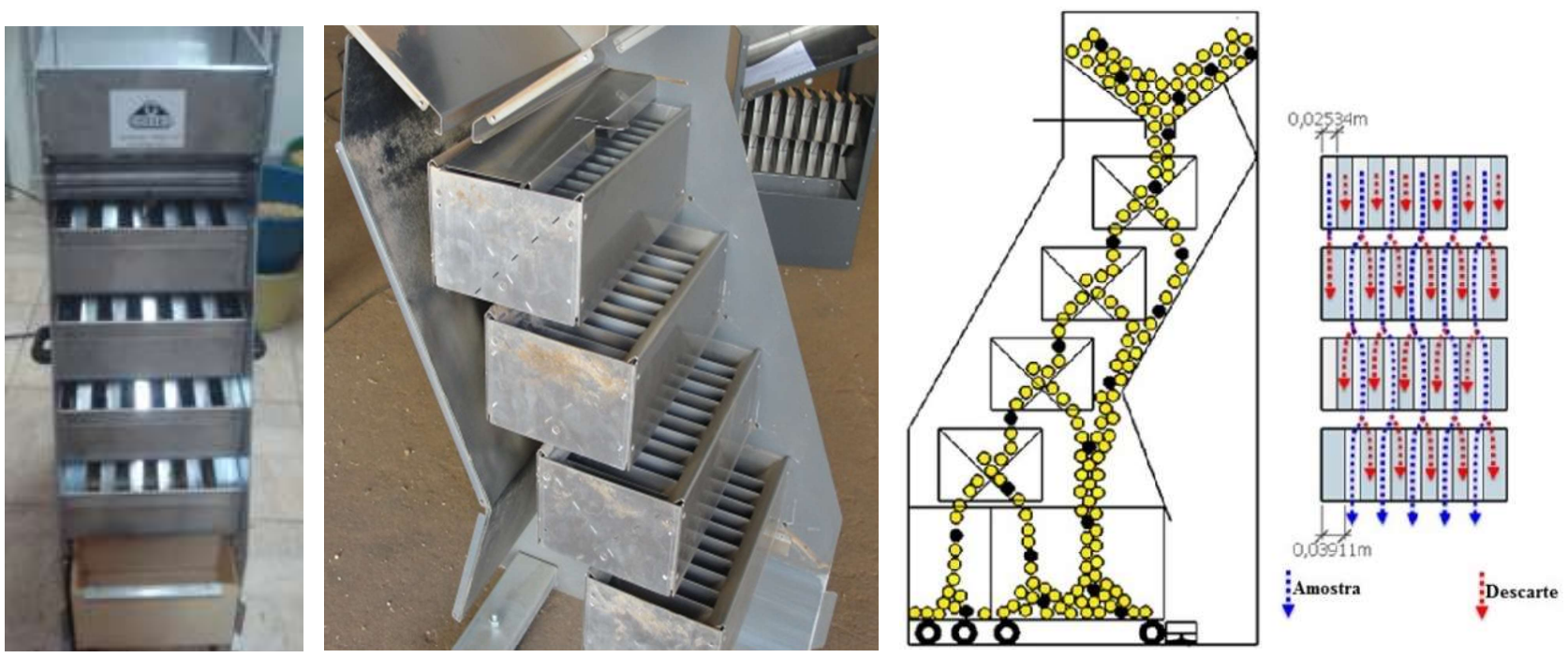

Figura 4. Esquema de homogeneização e diluição nos quarteadores multicanais 16:1 com detalhamento das canaletas.

Os quarteadores multicanais com redução de 4:1 apresenta dimensão de 0,45 $\mathrm{m}$ de largura, 0,41 $\mathrm{m}$ de comprimento e $0,64 \mathrm{~m}$ de altura e consiste na montagem de dois quarteadores menores (estágios) sobrepostos, sendo o primeiro quarteador formado por 18 canaletas (nove destinadas para a amostra com espessura média de $0,0252 \mathrm{~m}$, com uma canaleta na lateral com espessura de $0,016 \mathrm{~m}$, e também nove canais destinados para o descarte com espessura média de $0,0252 \mathrm{~m}$ ), conforme ilustrado na Figura 5 . Este primeiro quarteador reduz e leva parte da amostra para descarte, e a amostra passa em um segundo quarteador com 17 canaletas (9 canaletas para a amostra e 8 para descarte), que também divide os grãos, 


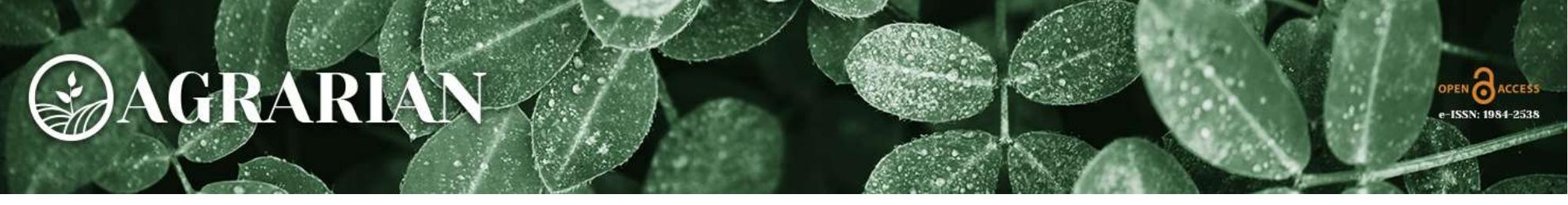

sendo parte destinada para descarte e a outra para amostra de trabalho. Neste equipamento, é necessário passar mais de uma vez para redução da amostra de trabalho.
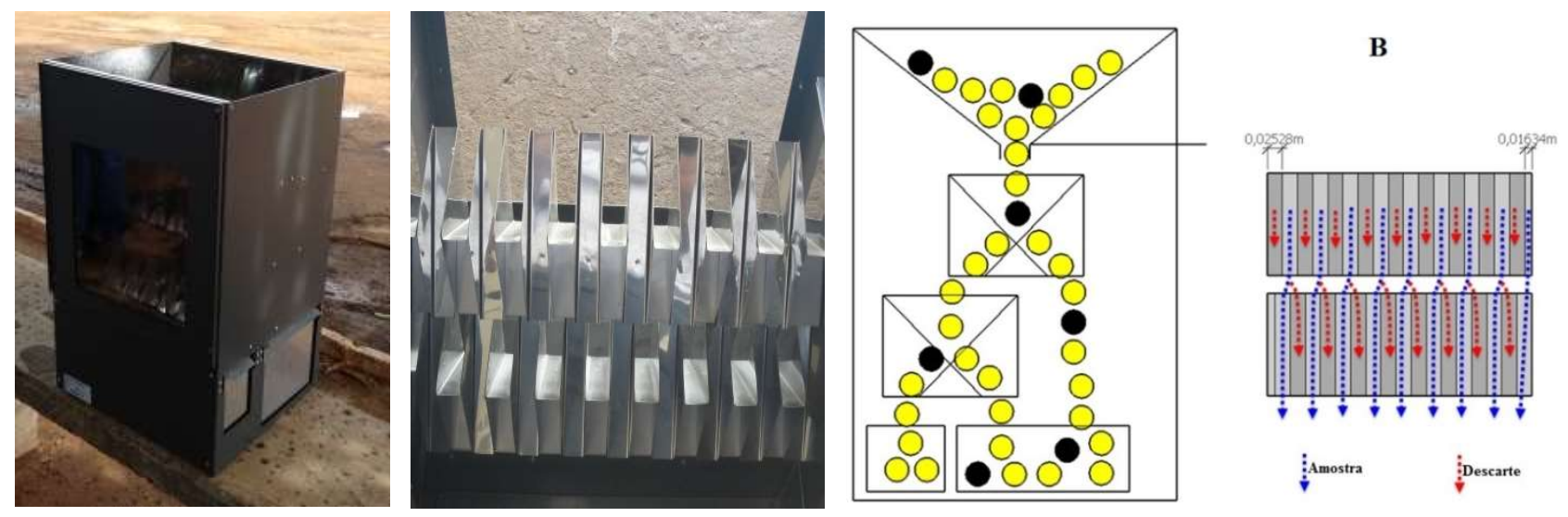

Figura 5. Esquema de homogeneização e diluição nos quarteadores multicanais $4: 1$ com detalhamento das canaletas.

O homogeneizador tipo Boerner apresenta uma moega para disposição da amostra, que tem um registro que é aberto quando se deseja fazer a operação de homogeneização. Os grãos passam por um funil e caem aleatoriamente em um cone invertido que redistribui estes grãos em um diâmetro de 0,36 m. Este cone é composto por um conjunto de canaletas internas com dimensão de 0,0205 m, e em canaletas externas de $0,0247 \mathrm{~m}$, que são direcionadas para os funis interno e externo, sendo as amostras armazenadas em recipientes. São necessárias no mínimo duas homogeneizações (CANADA, 2016), para depois serem feitas as diluições. São necessárias várias passagens dependendo da massa final da amostra de trabalho (Figura $6)$.
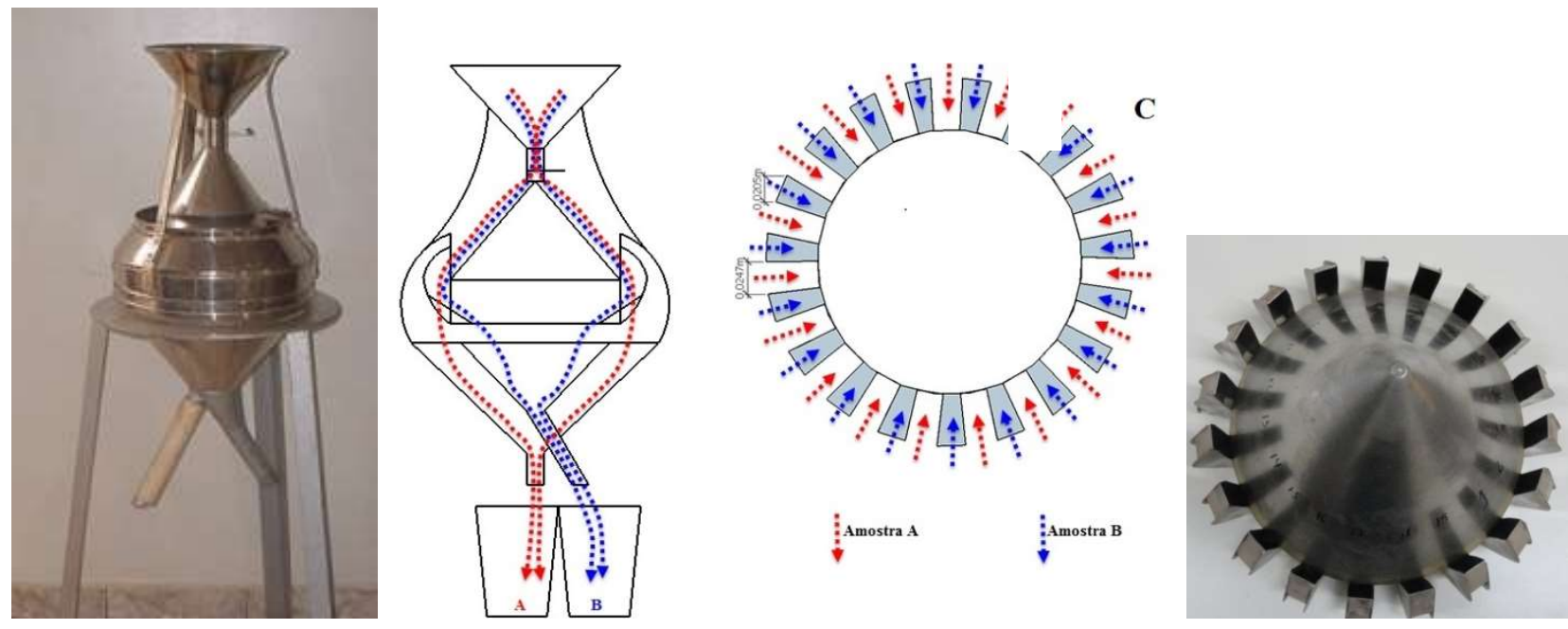

Figura 6. Esquema de diluição de amostras no homogeneizador tipo Boerner com detalhamento das canaletas.

O homogeneizador e divisor de amostra tipo Boerner é o único equipamento aprovado para homogeneização e divisão de amostras pela Canadian Grain Commission (CANADA, 2016). Na norma ISO 24333 (ISO, 2009), a indicação não é exclusiva do homogeneizador tipo Boerner, sendo também indicado para grãos o quarteador de ferro (superfície), divisores tipo quarteador (múltiplas ranhuras) com o mínimo de 18 canais, e também o divisor mecânico centrífugo para pequenas amostras.

A RY 1075/94 norma XXII (SENASA, 1994) da Argentina, recomenda para homogeneização e divisão da amostra, a utilização do equipamento tipo Boerner ou um similar que produza resultado semelhante. $O$ United States Department of Agriculture (USDA, 2009) recomenda a utilização do divisor e homogeneizador 
de amostras tipo Boerner ou qualquer outro dispositivo que forneça resultado equivalente ao reduzir a amostra em tamanho e grau de precisão requerido.

Durante a operação estes homogeneizadores permitem pouca interferência dos operadores. O Boerner demanda maior número de passagens da mesma amostra até atingir a massa de trabalho exigida e também necessita de maior tempo para homogeneização emitindo elevado nível de ruídos na sala de operação.

O quarteador multicanal 4:1 exige maior número de passagens em relação ao multicanal 16:1, e também torna o trabalho mais lento. No entanto, ambos os quarteadores apresentam nível de ruído suportável, sendo ainda menor para o multicanal 16:1, que exige menor número de passagem de acordo com o tamanho da amostra de trabalho utilizada, sendo, consequentemente, o equipamento que gasta menor tempo no preparo da amostra.

\section{Conclusões}

Diante o exposto, as unidades armazenadoras devem utilizar métodos de amostragem que ofereçam segurança na coleta e na classificação do produto, gerando os descontos necessários e otimizando as operações unitárias do pré-processamento dos grãos. Os equipamentos homogeneizadores de grãos devem ser eficientes na uniformização e divisão da amostra, além de apresentar rapidez e baixo nível de ruídos durante a operação.

\section{Agradecimentos}

Ao IF Goiano, CAPES, FAPEG, FINEP, CNPq e Caramuru S.A. pelo apoio.

\section{Referências}

AIDYN, C. Some engineering properties of peanut and kernel. Journal of Food Engineering, n. 79, n.3, p. 810-816, 2007.

BRASIL. Ministério da Agricultura, Pecuária e Abastecimento. Instrução Normativa $n^{\circ} 29$, de 8 de junho de 2011. Aprova os requisitos técnicos obrigatórios e recomendados para certificação de unidades armazenadoras. Diário Oficial da República Federativa do BRASIL, Brasília, 8 de jun. $2011 a, n^{\circ} 15$, Seção 1, p. 12-32.

BRASIL. Ministério da Agricultura, Pecuária e Abastecimento. Instrução Normativa $n^{\circ} 54$ de 24 de novembro de 2011. Aprova os requisitos, critérios e prazos para autorizar por meio de credenciamento as pessoas jurídicas de direito público ou privado a prestar ou executar serviços de classificação de produtos vegetais, seus subprodutos e resíduos de valor econômico, com base nos Padrões Oficiais de Classificação, na forma desta Instrução Normativa. Diário Oficial da República Federativa do BRASIL, Brasília, 25 de nov. 2011b, Seção 1, p. 5-6.

BRASIL. Ministério da Agricultura, Pecuária e Abastecimento. Instrução Normativa $n^{\circ} 11$, de 15 de maio de 2007. Estabelece o Regulamento Técnico da soja. Diário Oficial da República Federativa do BRASIL, Brasília, 16 mai. 2007, n 93, Seção 1, p. 13-15.

CANADA. 2016. Canadian Grain Commission approved sample dividing equipment. Disponível em: <http://www.grainscanada.gc.ca/quality-qualite/sg-eg-eng.htm>. Acesso em 24 fev. 2016.

FAO. Food and Agriculture Organization. Manual of Goods Practices for the Feed Industry - Section 5 Methods of Sampling and Analysis. p. 53-58, 2017. Acesso site: http://www.fao.org, abril 2017.

GLÓRIA, E.M. A qualidade de grãos da América Latina para exportação. In: SCUSSEL, V. M.; ROCHA, M. W. da; LORINI. I.; SABINO, M.; ROSA, C. A. da R.; CARVAJAL, M. M. (1 Ed.). Atualidades em micotoxinas e armazenagem qualitativa de grãos II. Florianópolis: Imprensa Universitária, 2008. cap. X, p.421-426.

ISO - International Organization for Standardization. Cereals and cereal products - Sampling. ISO 24333, First edition, Geneve, Switzerland, 2009. 36p.

PARIZZI, F.C. Classificação de produtos de origem vegetal. Lavras: UFLA/FAEPE, v.1, 1999. 61p. 
PAULSEN, M.R.; WATSON, S.A.; SINGH, M. Measurement and maintenance of corn quality. In: WHITE, J.P.; JOHN. L.A. CORN: Chemistry and Technology. Minnesota: AACC, p. 159-219, 2007.

QUIRINO, J.R. Avaliação de equipamentos e preparo de amostras para a classificação de grãos de soja. 2017. Ano de Obtenção: 2017. 71 f. Tese (Doutorado em Ciências Agrárias - Agronomia) - Instituto Federal de Educação, Ciência e Tecnologia Goiano - Campus Rio Verde, 2017.

SENASA - Serviço Nacional de Sanidade y Calidad Agroalimentaria - RY 1075/94. Norma XXII, Muestreo em granos, 1994. Disponível em: http://www.recibidoresdegranos.org/repository/normativas/norma22-engranos.pdf. Acesso em: 14/04/2017.

SIQUEIRA, V. C.; RESENDE, O.; CHAVES, T. H. Shape and size of jatropha beans (Jatropha curcas L.) during drying at different temperatures. Revista Ceres, v.60, n.6, p.820-825, 2013.

USDA - United State Department of Agriculture; grain inspection, packers and stockyards administration; federal grain inspection service. Grains Inspection handbook. Book II, chapter I, jul, 2013. Disponível em: http://www.gipsa.usda.gov/fgis/handbook/grain-insp/grbook2/general_info.pdf Acessado em 03 abril 2017.

USDA - UNITED STATES DEPARTMENT OF AGRICULTURE. Inspecting Grain-Practical Procedures for Grain Handlers. Washington, DC: USDA, 2009. 90p.

WHITAKER, T.B. Sampling granular foodstuffs for aflatoxin. Pure and Applied Chemistry, v.49, n.5024, p.1709-1717, Pergamom Press 1977.

WHITAKER, T.B.; WHITAKER, T.B.; SLATE, A.B.; DOKO, M.B.; MAESTRONI, B.M.; CANNAVAN. Sampling procedures to detect mycotoxins in agricultural commodities. New York: springer, 2011, 58p. 